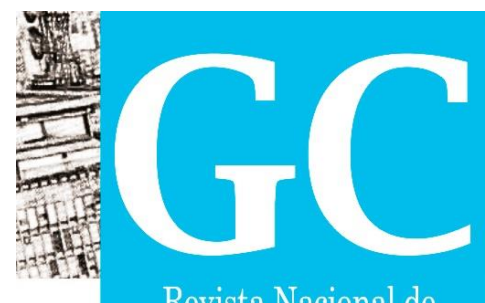

Revista Nacional de

Gerenciamento de Cidades

\title{
RESÍDUOS SÓLIDOS: ESTUDO SOBRE A ATUAL SITUAÇÃO NO MUNICIPIO DE SÃO JOÃO DEL-REI/MG
}

\author{
Arlon Cândido Ferreira ${ }^{1}$
}

\section{Leonardo Cristian Rocha ${ }^{2}$}

\section{Múcio do Amaral Figueiredo ${ }^{3}$}

RESUMO: A questão ambiental atualmente é motivo de discussão, principalmente quando o objetivo é equilibrar o desenvolvimento econômico e o meio ambiente. Destacase, nesse contexto, a produção e disposição dos resíduos sólidos. Diante dessa perspectiva, o objetivo desse trabalho é realizar o levantamento das legislações vigentes referentes a resíduos sólidos, tendo como exemplo, o estudo de caso de são João delRei, que possui problemas referentes esse tema. Para isso, foram realizadas entrevistas, consultas a órgãos públicos que forneceram informações que resultaram na geração de tabelas e na confecção de mapas. De acordos com os dados levantados observou-se a ausência de uma estrutura organizacional administrativa e planejamento das gestões anteriores. De acordo com a lei 12305/2010 a atual gestão terá que se adequar e fazer cumprir a legislação vigente, sob pena de não receber o Fundo de Participação dos Municípios (FPM), sendo este a principal fonte de receita dos municípios de pequeno a médio porte.

Palavra-Chave: Resíduos Sólidos. São João del-Rei. Saneamento.

\footnotetext{
${ }_{1}^{1}$ Graduando em Geografia (Bacharelado) - Universidade Federal de São João del-Rei / arloncf@gmail.com 2 Professor Dr. Departamento de Geociências - Universidade Federal de São João del-Rei / rochageo@ufsj.edu.br

3 Professor Dr. Departamento de Geociências - Universidade Federal de São João del-Rei / muciofigueiredo@ufsj.edu.br
} 

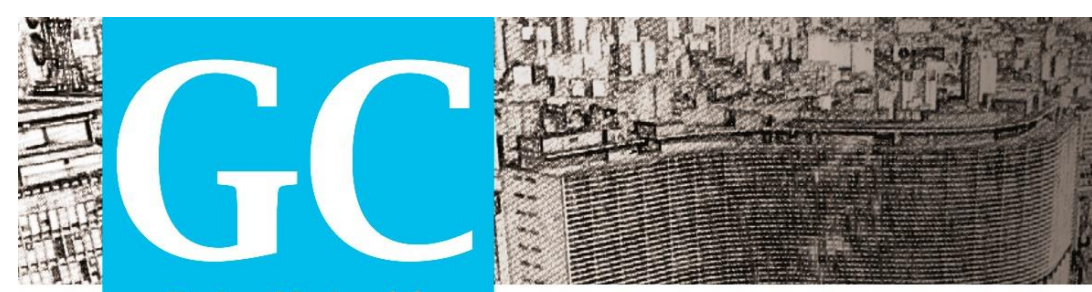

Revista Nacional de

Gerenciamento de Cidades

\section{INTRODUÇÃO}

A questão ambiental atualmente é uma das principais discussões no mundo atual. Desde Estocolmo 1972 veem ocorrendo em todo o globo com objetivo de equilibrar a situação do desenvolvimento econômico com a questão ambiental, tentando alcançar o equilíbrio entre os interesses econômicos e o meio ambiente, levando à melhoria da qualidade de vida das pessoas e a obtenção do desenvolvimento sustentável.

O modelo econômico atual, caracterizado pela produção e consumo em massa, tem gerado um intenso processo de urbanização e aumento populacional, criando diversos problemas ambientais no meio urbano das pequenas, médias e grandes cidades, tendo se destacado a questão dos resíduos sólidos.

Resíduos Sólidos são: (NBR 10004, 1987)

[...] aqueles resíduos nos estados sólido e semi-sólido, que resultam de atividades da comunidade de origem industrial, doméstica, hospitalar, comercial, agrícola, de serviços e de varrição. Ficam incluídos nesta definição os lodos provenientes de sistemas de tratamento de água, aqueles gerados em equipamentos e instalações de controle de poluição, bem como determinados líquidos cujas particularidades tornem inviável o seu lançamento na rede pública de esgotos ou corpos de água, ou exijam para isso soluções técnicas e economicamente inviáveis em face a melhor tecnologia disponível.

Os primeiros problemas relacionados com resíduos sólidos surgiram a partir do momento que o homem começou a extrair da natureza mais do que necessitava para sobreviver, resultando na necessidade de armazenamento do excedente para consumo e das sobras quando se tratava de resíduos orgânicos (Dionysio \& Dionysio, 2013). Na Idade Média, o lixo era jogado nas ruas e nas cidades, provocando epidemias que causaram a morte de milhares de pessoas.

No Brasil, a questão dos resíduos começou ser preocupação quando Dom Pedro II, em novembro de 1880, assina o decreto 3.024 aprovando o contrato de limpeza e irrigação da Cidade de São Sebastião do Rio de Janeiro, capital do Brasil Império naquela época. (Velloso, Santos \& Anjos, 1997).

Com a explosão do consumo pós II Guerra Mundial e, mais recentemente, com o surgimento dos produtos descartáveis, aliados ao crescimento populacional, a geração de 

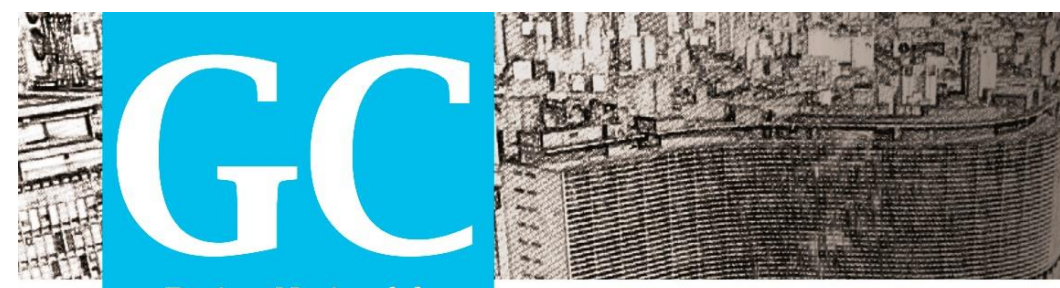

Revista Nacional de

Gerenciamento de Cidades

resíduos sólidos assumiu proporções gigantescas, sendo apontada como uma das maiores vilãs ambientais da atualidade. (Gurgel, 2009).

Sendo, que na década de 1980 os estudos sobre Meio Ambiente voltaram suas atenções para o controle da geração dos resíduos, esse interesse explica-se, pelo desenvolvimento de uma industrialização galopante, que produz cada vez mais bens de baixa durabilidade que logo devem ser substituídos por outros mais modernos, com novas funções e desenhos. (Leonard, 2011).

A solução encontrada para o destino dos resíduos sólidos na maioria dos locais ainda consiste em conduzi-lo para regiões afastadas da malha urbana. Segundo a Pesquisa Nacional de Saneamento Básico (PNSB), realizada pelo Instituto Brasileiro de Geografia e Estatística (IBGE, 2008), caracterizou o Brasil como produtor diário de 188,8 toneladas de resíduos diariamente. Quanto à destinação final, indicam que 50,8\% dos municípios depositam seus resíduos em lixões, 26,7\% utilizam aterros sanitários e 22,5\% dispõem de resíduos em aterros controlados.

Diante dessa perspectiva, o objetivo desta pesquisa é realizar o levantamento das legislações vigentes referentes à Política de Resíduos Sólidos, tendo como exemplo o estudo de caso do Município de São João del-Rei, município este, que possui graves problemas no que se refere a disposição e o tratamento de resíduos.

\section{A LEGISLAÇÃO NACIONAL SOBRE RESÍDUOS SÓLIDOS}

$\mathrm{Na}$ legislação vigente, a gestão de resíduos sólidos apresenta algumas características diferenciadas nas três esferas governamentais, tendo o governo um papel importante no estabelecimento de leis e normas que devem ser observadas por toda a sociedade, além da função fiscalizadora, estabelecendo um processo de mudança na sociedade sobre a forma de pensar, de sentir e de agir.

O Governo Federal desde 1991 propõe ações para criação de uma Política de Resíduos Sólidos, sendo marcada por alguns atos, tais como: 

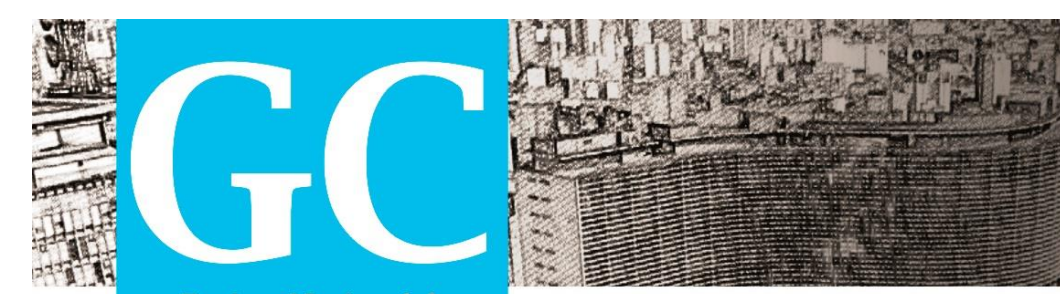

Revista Nacional de

Gerenciamento de Cidades

- 1991 - Projeto de Lei 203 dispõe sobre acondicionamento, coleta, tratamento, transporte e destinação dos resíduos de serviços de saúde.

- 2001 - Câmara dos Deputados cria e implementa a Comissão Especial da Política Nacional de Resíduos com o objetivo de apreciar as matérias contempladas nos projetos de lei apensados ao Projeto de Lei 203/91 e formular uma proposta substitutiva global.

- 2003 - O governo Federal institui o Grupo de Trabalho Interministerial de Saneamento Ambiental a fim de promover a integração das ações de saneamento ambiental, no âmbito do governo federal. O Grupo de Trabalho reestrutura o setor de saneamento e resulta na criação do Programa Resíduos Sólidos Urbanos.

- 2004 - O Ministério do Meio Ambiente promove grupos de discussões interministeriais e de secretarias do ministério para elaboração de proposta para a regulamentação dos resíduos sólidos. Em agosto do mesmo ano, o CONAMA realiza o seminário "Contribuições à Política Nacional de Resíduos Sólidos" com objetivo de ouvir a sociedade e formular nova proposta de projeto de lei.

- 2005 - Cria-se o grupo interno na Secretaria de Qualidade Ambiental nos Assentamentos Humanos do Ministério do Meio Ambiente para consolidar contribuições do Seminário CONAMA, os anteprojetos de lei existentes no Congresso Nacional e as contribuições dos diversos atores envolvidos na gestão de resíduos sólidos. Encaminhado o anteprojeto de lei de "Política Nacional de Resíduos Sólidos", debatido com Ministérios das Cidades, da Saúde, mediante sua Fundação Nacional de Saúde - Funasa, do Desenvolvimento, Indústria e Comércio Exterior, do Planejamento, Orçamento e Gestão, do Desenvolvimento Social e Combate à Fome e da Fazenda.

- 2006 - Aprovado relatório que trata do PL 203/91 acrescido da liberação da importação de pneus usados no Brasil.

- 2007 - Executivo propõe, em setembro, o PL 1991. O projeto de lei da Política Nacional de Resíduos Sólidos considerou o estilo de vida da sociedade contemporânea, que aliado às estratégias de marketing do setor produtivo, leva a um consumo intensivo provocando uma série de impactos ambientais, à saúde 

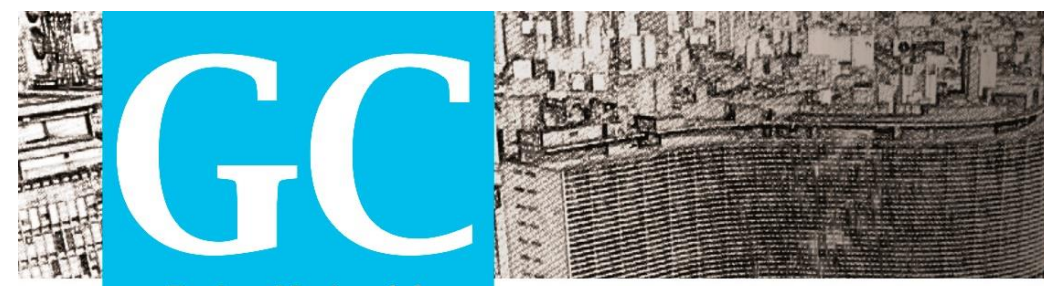

Revista Nacional de

Gerenciamento de Cidades

pública e sociais incompatíveis com o modelo de desenvolvimento sustentável que se pretende implantar no Brasil.

Após 19 anos de negociações e legislações inacabadas referente à temática de resíduos sólidos, o governo federal em 02 de Agosto 2010 instituiu a lei 12.305 referente à Política Nacional de Resíduos Sólidos - PNRS. A referida lei se tornou um instrumento importante para permitir o avanço necessário ao país para o enfrentamento desta questão.

\section{A LEGISLAÇÃO ESTADUAL SOBRE RESÍDUOS SÓLIDOS}

Minas Gerais começou as suas ações em 2001, quando o Conselho Estadual de Política Ambiental de Minas Gerais (COPAM), lançou a Deliberação Normativa 52/2001, deixando claro uma política de erradicação dos lixões no estado.

Em 2009, foi publicado a Política Estadual de Resíduos Sólidos (lei 18.031), que define a Gestão Integrada dos Resíduos Sólidos Urbanos, como conjunto articulado de ações políticas, normativas, operacionais, financeiras, de educação ambiental e de planejamento desenvolvidas e aplicadas aos processos de geração, segregação, coleta, manuseio, acondicionamento, entre outras ações. Como essa política é difícil de ser implementada, devido a sua complexidade e valor, os municípios começaram a se organizar para formar consórcios com esse fim, ancorados pela lei federal 11.107/2005, Lei dos Consórcios Públicos e da Gestão Associada de Serviços Públicos e seu respectivo regulamento.

\section{SÃO JOÃO DEL REI E A SITUAÇÃO DOS RESIDUOS SOLIDOS: UM ESTUDO DE CASO}

São João del-Rei está localizada na mesorregião do Campos das Vertentes, estado de Minas Gerais. A população deste município é de 84.469 habitantes, sendo 79.857 moradores da zona urbana e 4.612 moradores da zona rural. A área territorial é de 

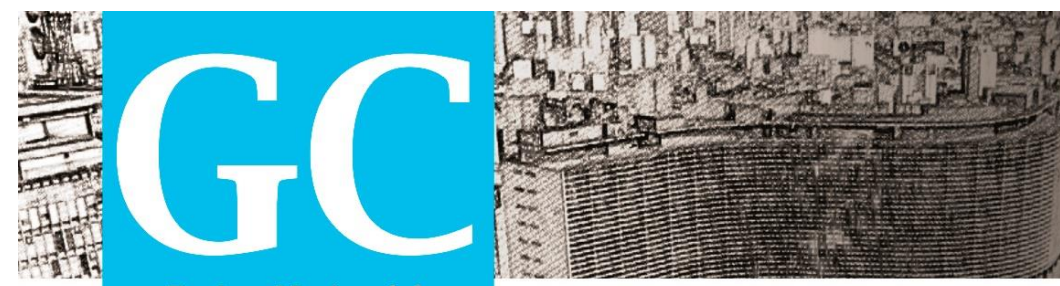

Revista Nacional de

Gerenciamento de Cidades

$1.464,327 \mathrm{Km}^{2}$, onde estão situados 27.313 domicílios. O município possui graves problemas no que se refere ao tratamento de resíduos sólidos, tendo a seguinte legislação acerca do tema:

- Lei 2.646 de 17 de dezembro de 1990, que Estabelece o novo Código de Posturas do Município de são João del-Rei e dá outras providencias.

- Decreto 2.371, de 10 de julho de 1997 que proibi o deposito de lixo em vias públicas, logradouros e córregos.

- Lei 4.546 de 29 de dezembro de 2010, dispõe sobre o recolhimento e destinação dos pneus inservíveis no Município de São João del-Rei e, dá outras providencias.

- Lei 4.421 de 21 de dezembro de 2011 dispõe sobre o reconhecimento de pilhas, baterias, lâmpadas fluorescente, disquete, CDs DVDs e todo material tecnológico usado, objetivando da destinação final adequada e, dá outras providencias.

- Lei 4.821 de 30 de Outubro de 2012, que dispõe sobre a coleta seletiva de lixo no Município de São João del-Rei, e dá outras providencias.

Apesar do município ter uma legislação voltada para uma política adequada de Resíduos Sólidos, a cidade possui graves problemas referentes à disposição inicial, recolhimento e tratamento final dos resíduos. Esse lixo, quando não tratado adequadamente, pode ser responsável por impactos ambientais graves ao ambiente.

\section{MÉTODOS}

Para fundamentação do trabalho, foram realizadas algumas etapas:

- Primeira Etapa: Constitui-se na revisão da literatura nacional e internacional sobre a temática;

- Segunda Etapa: Entrevistas em órgãos municipais sobre a questão dos resíduos sólidos, onde os mesmos nos cederam diversos materiais para serem utilizados na pesquisa.

- Terceira Etapa: Após essas entrevistas, foram realizados trabalhos de campo no centro urbano com o intuito de coletar dados e registrar características locais sobre o tratamento, de modo geral, dos resíduos sólidos do município; 
Revista Nacional de

Gerenciamento de Cidades

- Quarta Etapa: Após os trabalhos de campo e análise de dados fornecidos pelos órgãos municipais e pelo IBGE, foram confeccionadas tabelas e produzidos os mapas.

- Quinta Etapa: Confecção de trabalho científico.

\section{RESULTADOS}

Devido à falta de lixeiras adequadas para o recebimento dos resíduos produzidos pela a população, nós deparamos com uma dura realidade no município. Nos trabalhos de campo realizados, foram identificados 40 locais com grandes concentrações irregulares de lixo (Tabela 01), onde destacamos os 28 mais críticos. (Figura 01). Essa disposição inadequada tornam os locais propícios à atração de animais, como: cavalos, cachorros, porcos (Figura 02), que acabam por se constituírem em grandes vetores de diversas doenças.

Tabela 01: Pontos irregulares de lixo nos bairros.

\begin{tabular}{cc}
\hline Bairros & Pontos irregulares de lixo \\
\hline Bonfim & 01 \\
Centro & 00 \\
Colônia do Marçal & 03 \\
Fábricas & 05 \\
Jardim Central & 03 \\
Matosinhos & 15 \\
Senhor dos Montes & 01 \\
Tejuco & 12 \\
Total & $\mathbf{4 0}$ \\
\hline
\end{tabular}



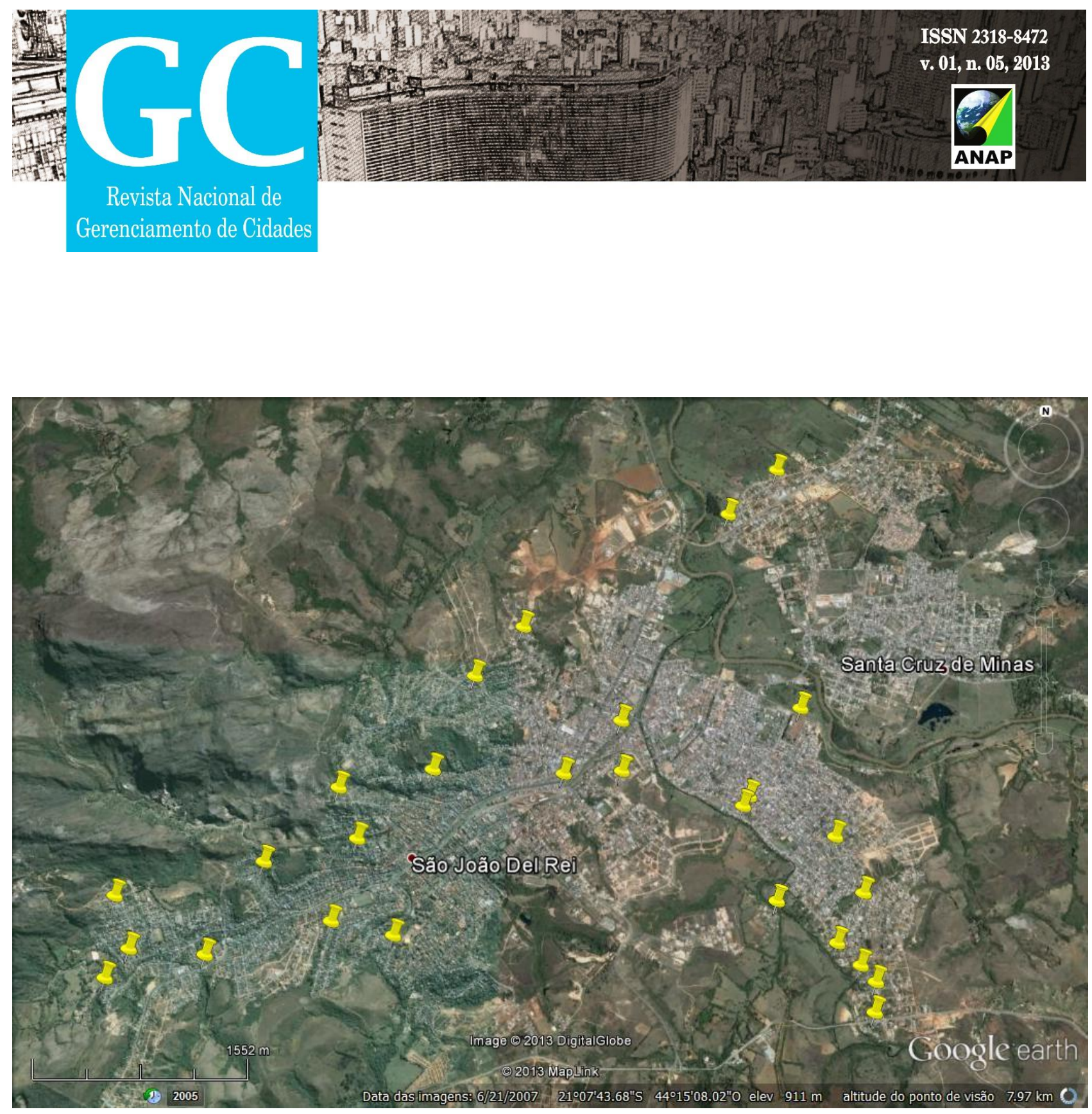

Figura 01: Mapa de localização de grandes concentrações de lixo 

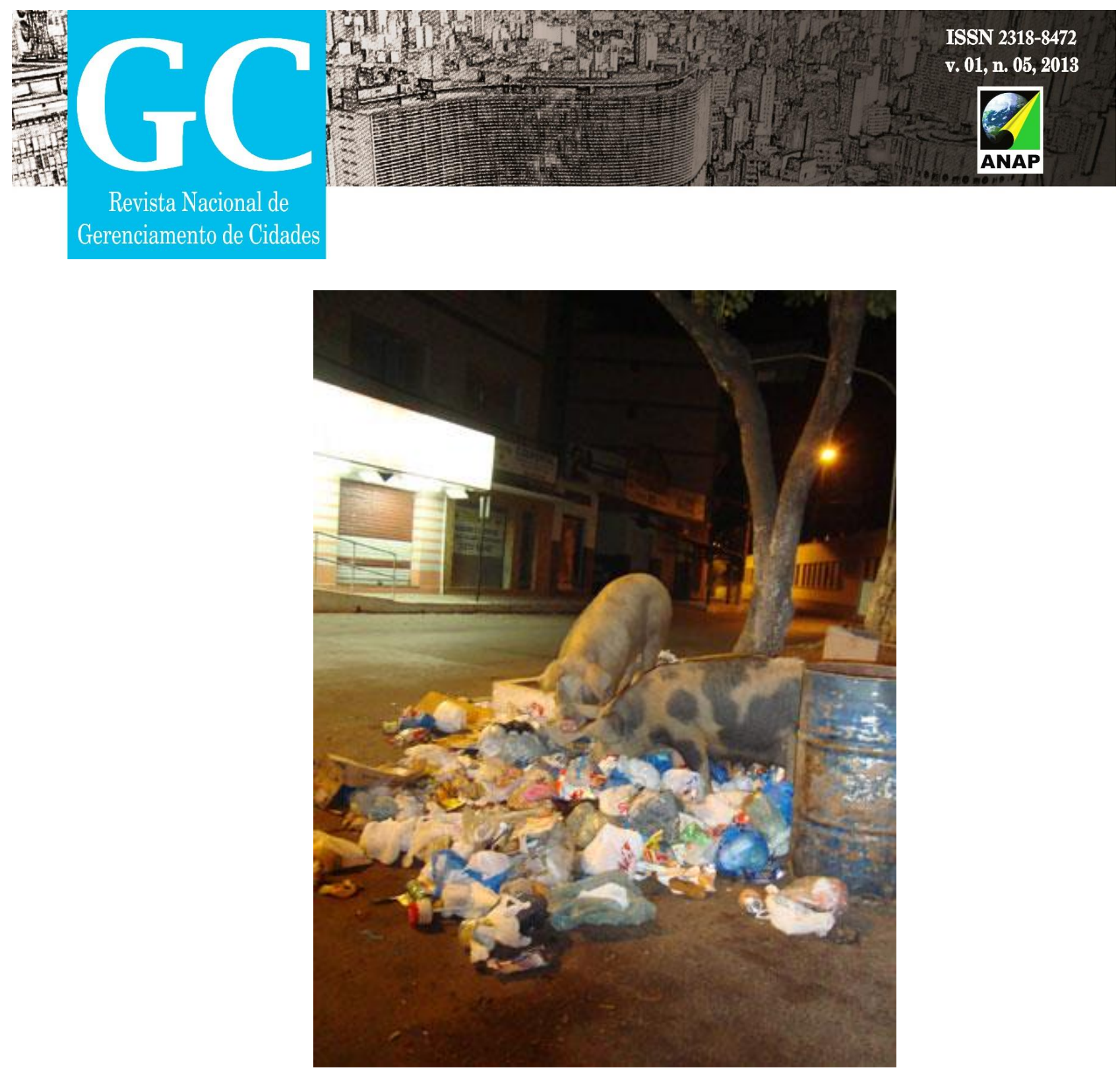

Figura 02: Porcos atraídos pelo lixo

Fonte: Jornal Folha das Vertentes

De acordo com a Tabela 02, 26.133 domicílios de São João del-Rei são atendidos por serviço de coleta domiciliar, porem, não adotam um horário de recolhimento especifico, sendo observados amontoados de lixo por diversos pontos da cidade.

Tabela 02: Destinação regular do lixo domiciliar.

\begin{tabular}{lc}
\hline \multicolumn{2}{c}{ Destino do Lixo Domiciliar (regulares) } \\
\hline \multicolumn{1}{c}{ Forma de Descarte } & Domicílios \\
Coletado por serviço de limpeza & 25.596 \\
Coletado em caçambas de serviços de limpeza & 537 \\
Total de domicilio & $\mathbf{2 6 . 1 3 3}$ \\
\hline
\end{tabular}




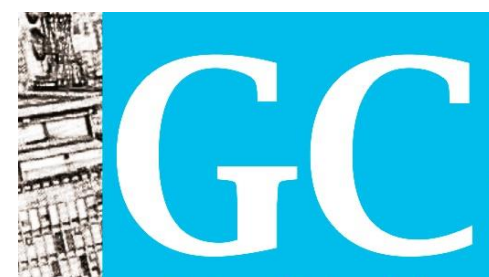

Revista Nacional de

Gerenciamento de Cidades

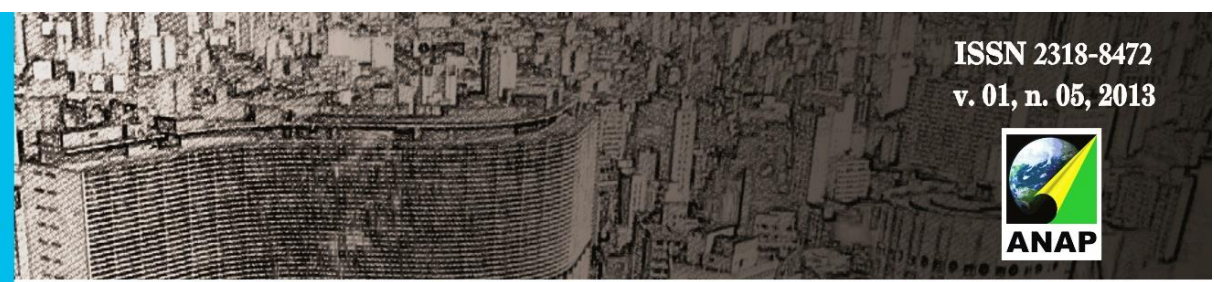

Fonte: IBGE - Censo Demográfico 2010

Outro problema encontrado na coleta de lixo domiciliar é a falta de acesso a algumas regiões do município, por dificuldade de infraestrutura urbana (ruas estreitas pelo fato do município ser histórico) e íngreme. Nessas regiões é comum a destinação inadequada dos resíduos gerados (Tabela 03).

Tabela 03: Destinação irregular do lixo domiciliar.

\begin{tabular}{lc}
\hline \multicolumn{2}{c}{ Destino do Lixo Domiciliar (irregulares) } \\
\hline \multicolumn{1}{c}{ Forma de Descarte } & Domicílios \\
Queimado (na propriedade) & 1.033 \\
Enterrado (na propriedade) & 19 \\
Jogado em terreno baldio ou rua & 70 \\
Jogado em rio/lago & 8 \\
Outro Destino & 50 \\
Total de domicilio & $\mathbf{1 1 8 0}$ \\
\hline
\end{tabular}

Fonte: IBGE - Censo Demográfico 2010

Paralelamente a coleta de lixo pública, São João del-Rei conta com a ASCAS Associação dos Catadores de Materiais Recicláveis de São João del-Rei criada em junho de 2004. Do total de material coletado e levado para a ASCAS, o papel constitui a maior parte, chegando a alcançar mais de $70 \%$ da produção total; em seguida, estão o plástico, o metal e o vidro. (Kemp,et. al. 2008)

Outra questão que merece atenção do poder público é a destinação incorreta de rejeitos de construção em bota fora irregulares. (Tabela 04 / Figura 04 e 05). Os bota fora geralmente são constituídos de materiais que geram intensa poeira, causando doenças respiratórias, alergias entre outros vetores de doença. Esses locais não apenas trazem doenças, mas causa desprendimento de solo devido à intensa movimentação de caminhões, provocando o carreamento dos resíduos para os cursos d'água, além dos materiais que são lixiviados para os aquíferos presentes na região. 

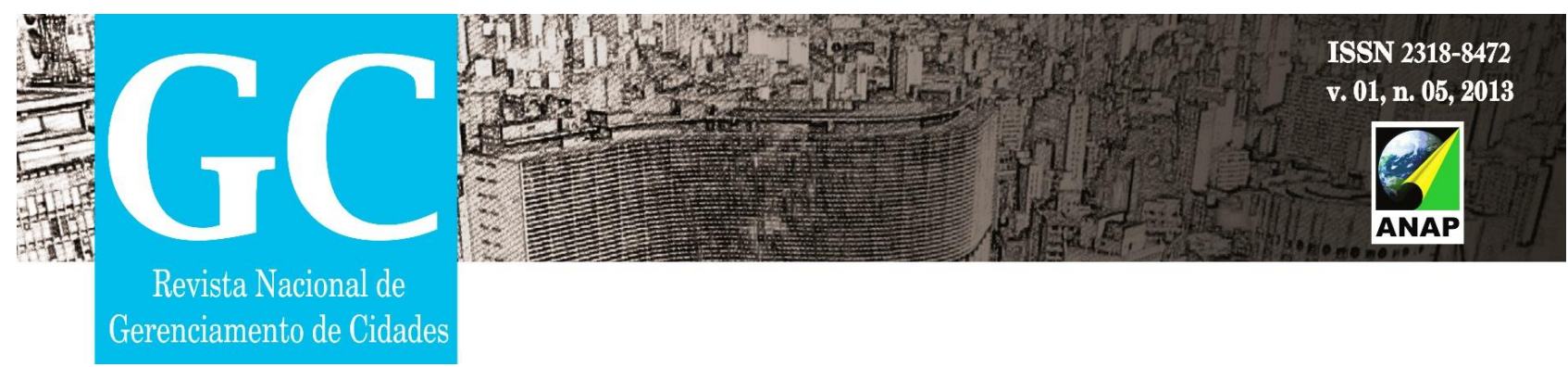

Tabela 04: Pontos irregulares de depósito de rejeitos de construção.

\begin{tabular}{cc}
\hline Bairros & Acumulo irregular de rejeitos de construção \\
\hline Bonfim & 02 \\
Centro & 00 \\
Colônia do Marçal & 01 \\
Fábricas & 02 \\
Jardim Central & 00 \\
Matosinhos & 04 \\
Senhor dos Montes & 00 \\
Tejuco & 00 \\
Total & 09 \\
\hline
\end{tabular}

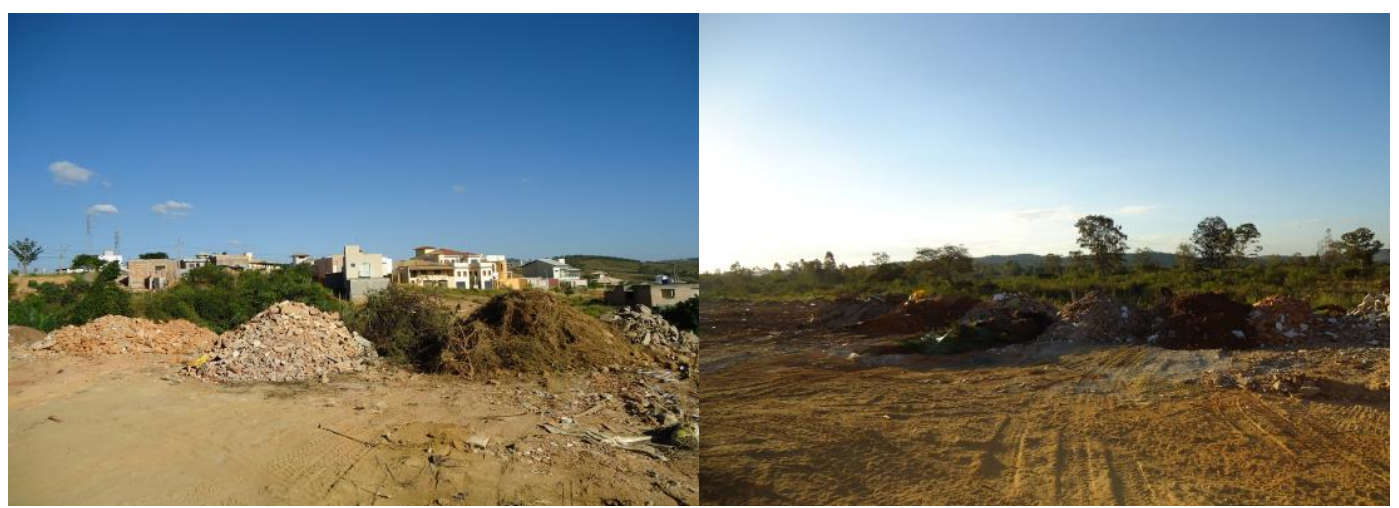

Figura 04: Locais irregulares de despejo de rejeitos de construção 

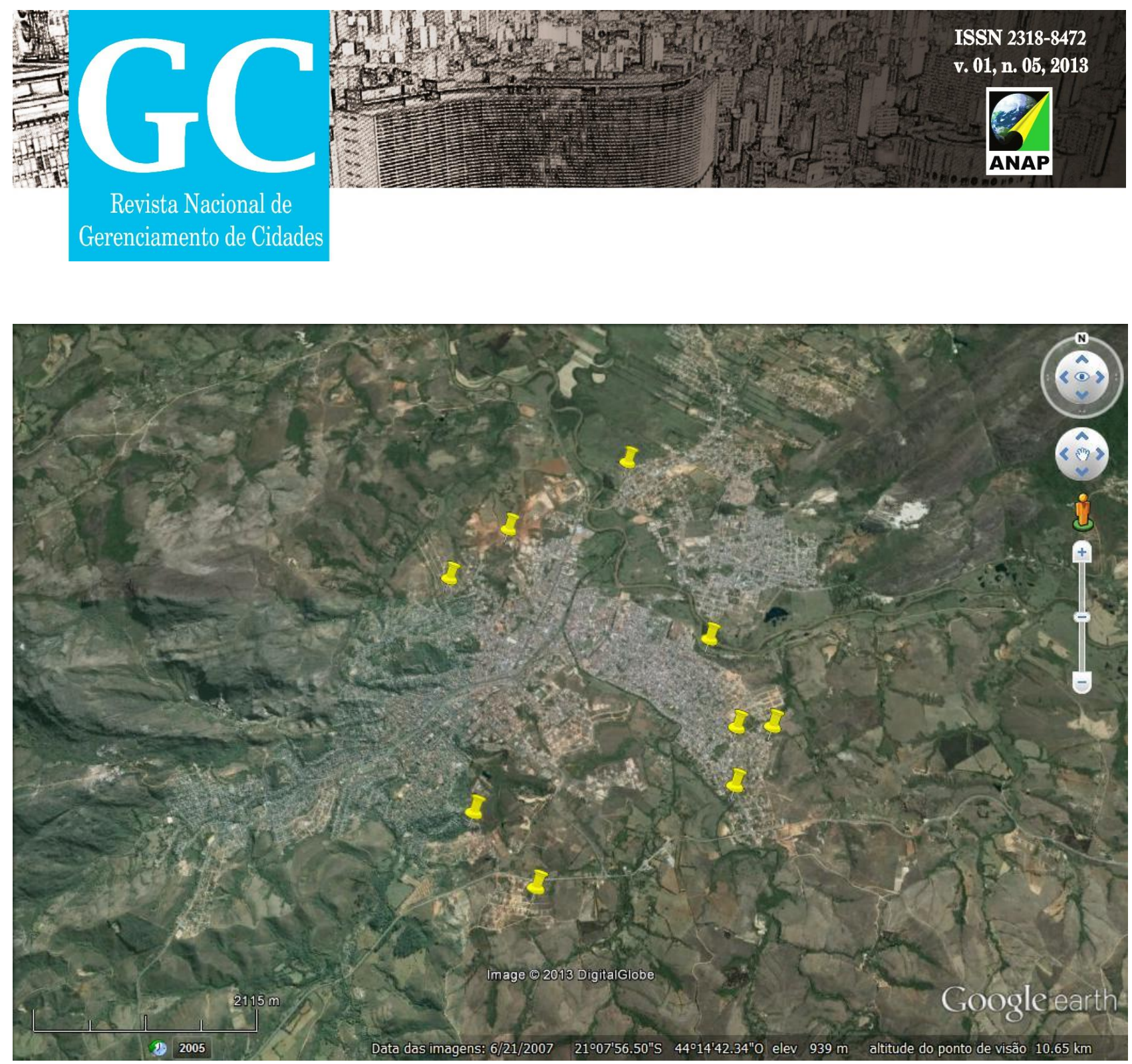

FIGURA 05: Mapa de localização de bota fora de resíduos de construção

Quando a disposição final dos resíduos coletados no município, o mesmo é lançado em um lixão localizado a cerca de 7,6 Km da BR 265, uma das principais entradas do município. O Lixão é definido pelo IPT, 2005 como:

Uma das formas mais inadequadas de disposição final de resíduos sólidos, que se caracteriza pela simples descarga do lixo sobre o solo, sem medidas de proteção ao meio ambiente ou á saúde pública. O mesmo que descarga de resíduos a céu aberto (IPT, 1995).

No lixão do município de São João del-Rei, foram observados diversas ações que desrespeita a Lei 18.301 de Janeiro de 2009, que dispõe sobre a política Estadual de Resíduos Sólidos. 


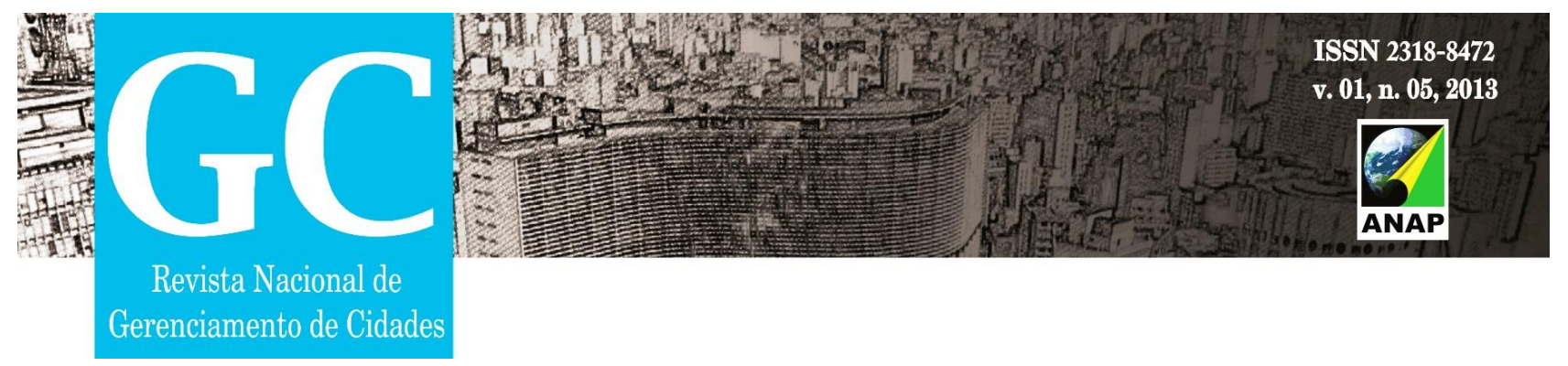

- Lançamento "in natura" a céu aberto, sem tratamento prévio, em áreas urbanas e rurais; (Figura 06a)

- Queima a céu aberto ou em recipientes, instalações ou equipamentos não licenciados para esta finalidade; (Figura 06b)

- A catação de resíduos sólidos em qualquer hipótese;

- A fixação de habitações temporárias ou permanentes. (Figura 06c)

a)

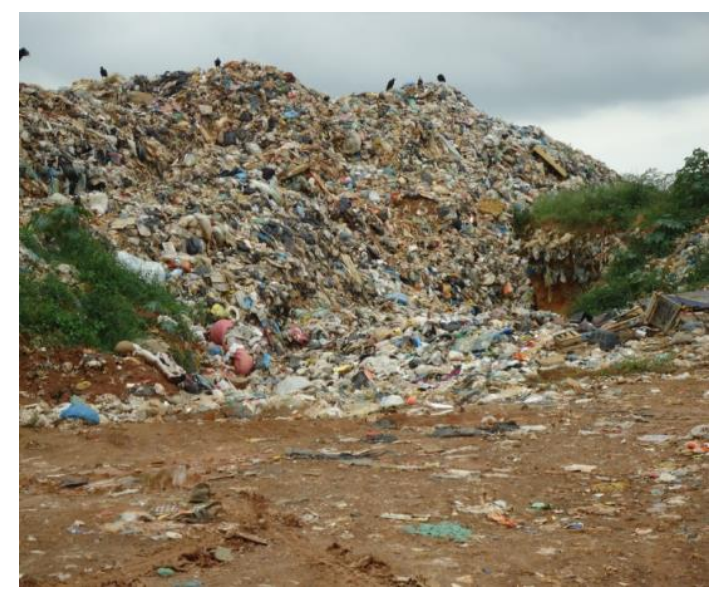

b)

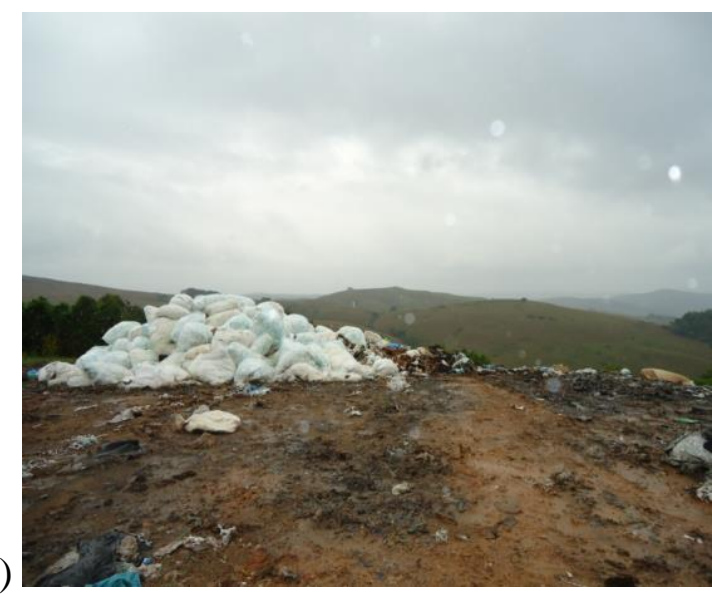

c)

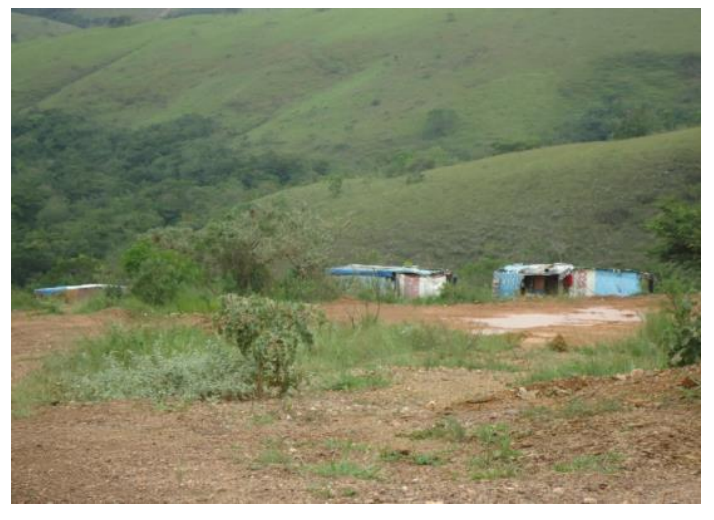

Figura 06: a) Lixo lançado in natura em solo sem proteção; b) evidencias de queimadas; c) residências irregulares na área do lixão.

Sendo o lixão a forma mais inadequada de disposição final do lixo, este é simplesmente depositado sobre o solo, sem qualquer ação de prevenção em relação a preservação ambiental. Este processo gera um grande risco de contaminação das águas do entorno pelo processo de lixiviação, pois o escorrimento de chorume é visível. Ao todo 


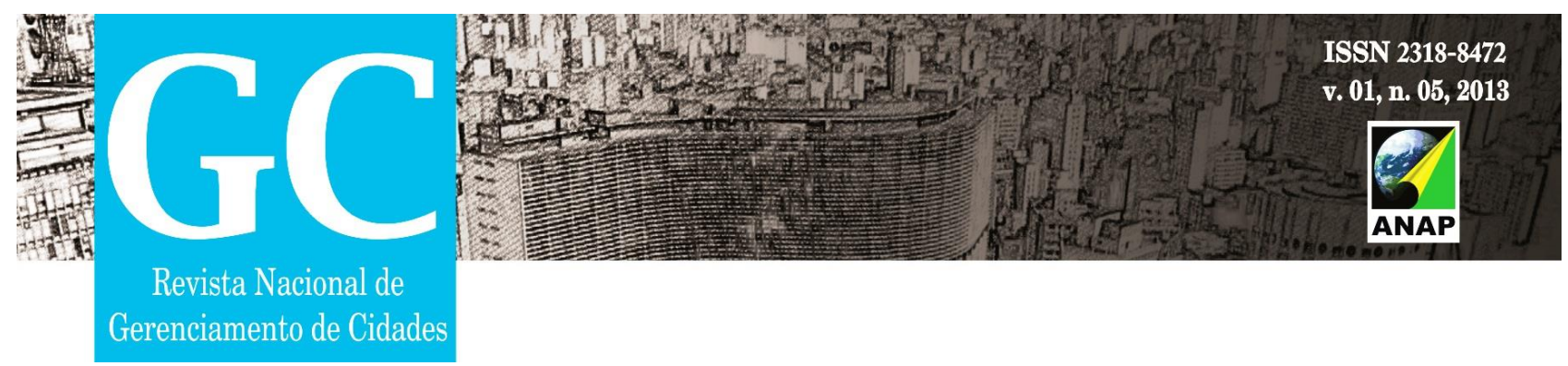

são depositados em torno de 90 toneladas dia, o qual não recebe nenhum tipo de tratamento.

Após esse levantamento ocorreram reuniões com os órgãos municipais, principalmente a Secretaria Municipal de Desenvolvimento Urbano e Sustentabilidade, a qual nos informou algumas melhorias referentes a política de resíduos sólidos:

- Criação do Consórcio Intermunicipal de Gestão e Desenvolvimento Ambiental Sustentável das Vertentes - CIGEDAS. Consórcio composto por 17 municípios da região, o qual gerenciará o Programa Regional de Resíduos Sólidos e sua implementação.

- Limpeza de Betas (antigas áreas de extração de ouro) que eram utilizadas como lixões clandestinos;

- Contratação de máquinas para compactação e cobertura final dos resíduos sólidos;

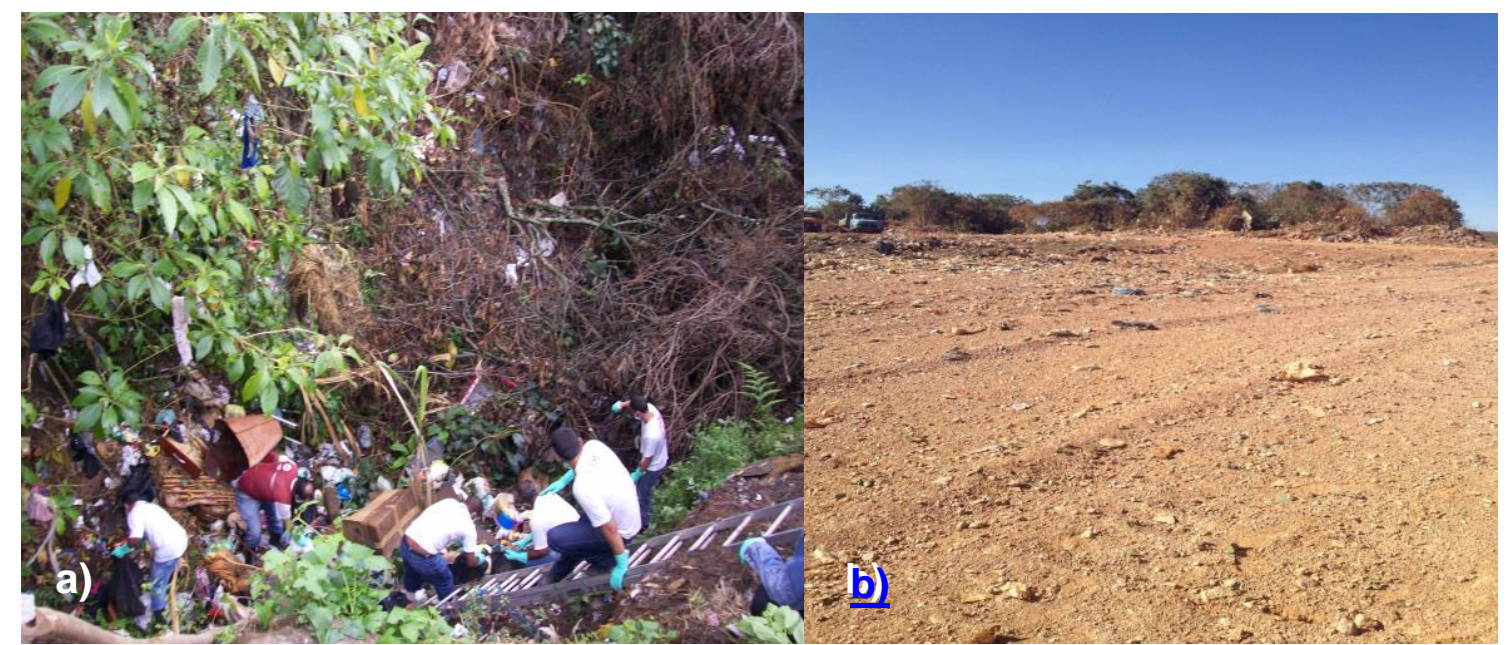

Figura 07: a)Limpeza de beta utilizada como lixão clandestino b)Cobertura realizada no lixo após destinação final

\section{CONCLUSÃO}

A problemática ambiental gerada pelo lixo é de difícil solução e a maior parte das cidades brasileiras apresenta um serviço de coleta que não prevê a segregação dos resíduos na fonte (IBGE, 2006).

Do ponto de vista social, os serviços públicos urbanos representam, ou deveriam 

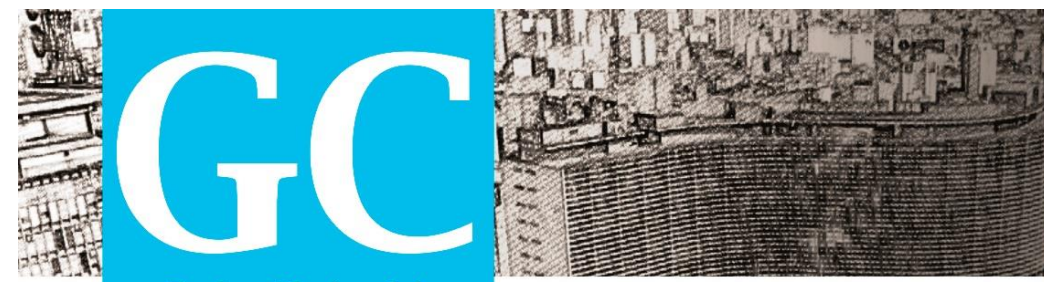

Revista Nacional de

Gerenciamento de Cidades

representar, garantias básicas para melhores condições de vida. Nesse sentido, serviços como transporte, água e coleta de lixo, entre outros, não deveriam ser pensados e planejados com base no imediatismo e tendo como pressuposto essencial o lucro. No entanto, algumas observações demonstram que esses serviços vêm sendo utilizados dentro de uma lógica apenas puramente de mercado.

A partir deste diagnóstico preliminar observou-se a ausência de uma estrutura organizacional administrativa e a falta de planejamento das gestões anteriores. Sendo, nosso dever, nortear o gerenciamento dos resíduos sólidos de forma adequada para o município.

\section{REFERENCIAS}

ASSOCIAÇÃO BRASILEIRA DE NORMAS TÉCNICAS. NBR 10004: resíduos sólidos: classificação. Rio de Janeiro, 1987.

DIONYSIO, Luis Gustavo Magro; DIONYSIO, Renata Barbosa. Lixo Urbano: Descarte e Reciclagem de Materiais. CCEAD/PUC Rio, 2013. http://web.ccead.pucrio.br/condigital/mvsl/Sala\%20de\%20Leitura/conteudos/SL_lixo_urbano.pdf.Acessado em 30/07/2013.

GURGEL, Fernanda Fernandes. Participação de Moradores no Programa de Coleta Seletiva em Três Bairros de Natal/RN: Explorando Determinantes Psico-SocioAmbientais. Tese de Doutorado. Programa de Doutora Integrado UFRN-UFPB em Psicologia Social. Natal, 2009.

INSTITUTO BRASILEIRO DE GEOGRAFIA E ESTATÍSTICA. Pesquisa Nacional de Saneamento Básico 2008. Rio de Janeiro, 2010.

INSTITUTO BRASILEIRO DE GEOGRAFIA E ESTATÍSTICA - IBGE. .Pesquisa nacional de saneamento básico - 2000. Disponível em: <http://www.ibge.gov.br/ibgeteen>. Acesso 


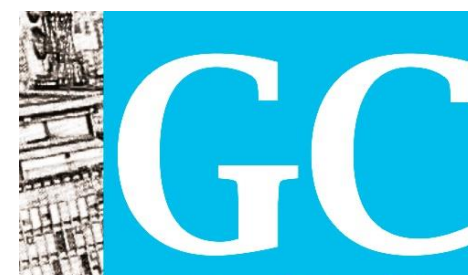

Revista Nacional de

Gerenciamento de Cidades

em: 23 jun. 2006.

INSTITUTO DE PESQUISAS TECNOLÓGICAS DO ESTADO DE SÃO PAULO (IPT). Lixo Municipal: Manual de Gerenciamento Integrado. São Paulo: IPT/CEMPRE. 1995. 278p.

LEONARD, Annie. A História das Coisas: da natureza ao lixo, o que acontece com tudo que consumimos. Rio de Janeiro: Zahar, 2011.

VELLOSO, M.P; SANTOS, E.M; ANJOS, L.A; Processo de Trabalho e Acidentes de Trabalho em Coletores de Lixo Domiciliar na Cidade do Rio de Janeiro. Caderno de Saúde, 13, 1997. 693-700.

KEMP, Valeria Heloisa; CRIVELLARI, Helena Maria Tarchi. Organizadoras. Catadores na Cena Urbana: Construção de Políticas Socioambientais. Belo Horizonte. Editora Autêntica, 2008. 